\title{
Types and Causes of Physiological Injury in Piano Playing, with Emphasis on Piano Pedagogy in China
}

\author{
Ruixi Niu \\ runiu@mix.wvu.edu
}

Follow this and additional works at: https://researchrepository.wvu.edu/etd

Part of the Music Pedagogy Commons, Music Performance Commons, and the Music Practice Commons

\section{Recommended Citation}

Niu, Ruixi, "Types and Causes of Physiological Injury in Piano Playing, with Emphasis on Piano Pedagogy in China" (2020). Graduate Theses, Dissertations, and Problem Reports. 7693.

https://researchrepository.wvu.edu/etd/7693

This Dissertation is protected by copyright and/or related rights. It has been brought to you by the The Research Repository @ WVU with permission from the rights-holder(s). You are free to use this Dissertation in any way that is permitted by the copyright and related rights legislation that applies to your use. For other uses you must obtain permission from the rights-holder(s) directly, unless additional rights are indicated by a Creative Commons license in the record and/ or on the work itself. This Dissertation has been accepted for inclusion in WVU Graduate Theses, Dissertations, and Problem Reports collection by an authorized administrator of The Research Repository @ WVU.

For more information, please contact researchrepository@mail.wvu.edu. 
Types and Causes of Physiological Injury in Piano Playing, with Emphasis on Piano Pedagogy in China

\title{
Ruixi Niu
}

\author{
A thesis submitted to \\ the College of Creative Arts \\ at West Virginia University
}

In partial fulfillment of the requirements for the degree of

Doctor of Musical Arts in

Piano Performance

\author{
Peter Amstutz, DMA, Chair \\ James Miltenberger, DMA \\ Matthew Heap, PhD \\ Sandra Schwartz, PhD \\ Bernie Schultz, PhD
}

School of Music

Morgantown, West Virginia

2020

Keywords: Physiological Injury, Piano Performance, Piano Pedagogy, China

Copyright @ 2020 Ruixi Niu 


\begin{abstract}
Types and Causes of Physiological Injury in Piano Playing, with Emphasis on Piano Pedagogy in China
\end{abstract}

\title{
Ruixi Niu
}

Among musicians who seek medical help for their injuries each year, half are pianists. Improper playing technique is a factor influencing the development of injury. This research project focuses on the types and causes of physiological injury in the process of piano playing and includes methods of avoiding such injuries.

The types of piano-related physiological injury and associated conditions that are discussed include tenosynovitis, focal dystonia, and muscle pain. Relevant literature and investigative data — and some legends — are compared and sorted. Chinese pedagogical views concerning piano technique are discussed, along with ongoing debates concerning injury prevention and the appropriate use of exercises in practice. Causes of injuries appear in five general categories: overuse, misuse, emotional stress, anatomical differences, and individual sensitivity.

This project combines the rational selection and scientific application of playing and practicing methods, based on personal physiological conditions in the actual piano-playing process. 


\section{Acknowledgements}

I would like to extend my sincerest gratitude to Dr. Peter Amstutz, my professor, mentor, and friend. His constant guidance and encouragement have been truly invaluable, both in the writing of this document and throughout the years of my DMA study. I am truly indebted for his patience, motivation, and keen intellect in music.

I extend my deep appreciation to all members of my committee: Dr. James Miltenberger, Dr. Matthew Heap, Dr. Sandra Schwartz, and Dr. Bernie Schultz, who offered me constant suggestions and support during my doctoral studies.

Special thanks to Dr. José Ramón Mendez, for stimulating discussions, insightful comments, and immense support during my musical journey.

I would also like to express my gratitude to Dr. Justin Massey, my best friend, my former roommate, and my editor, who sacrificed his time to raise my writing to a higher level.

Finally, I would like to thank my family for supporting and encouraging me during the compilation of this dissertation and throughout my entire life. 


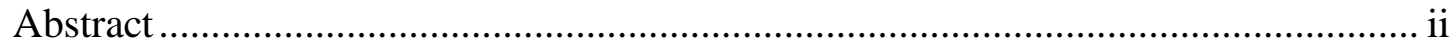

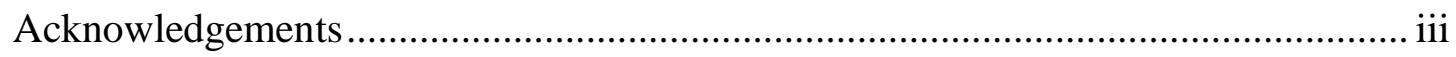

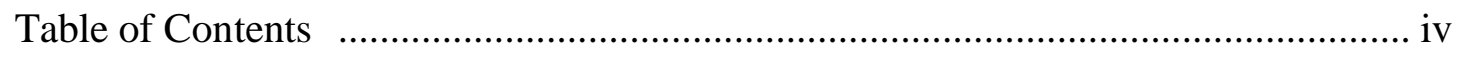

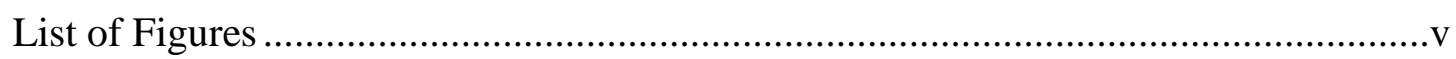

Chapter 1: Introduction ..................................................................................1

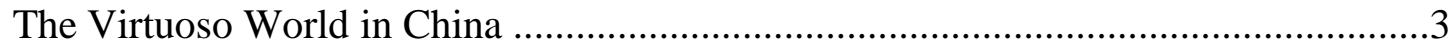

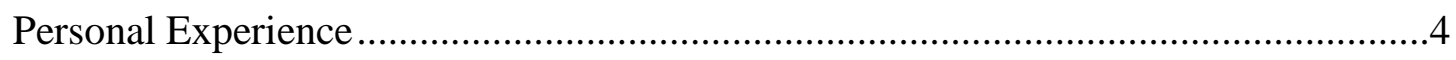

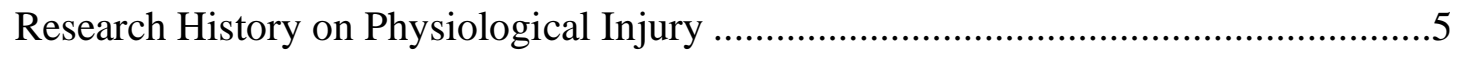

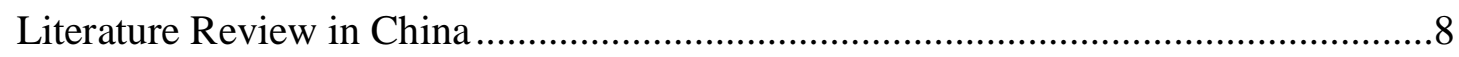

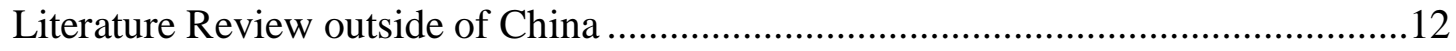

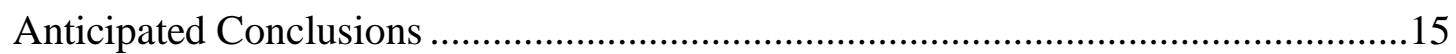

Chapter 2: Types of Physiological Injuries in Piano Playing ................................16

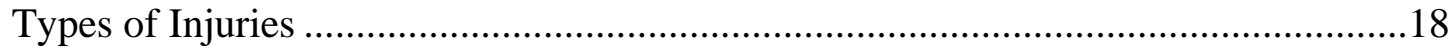

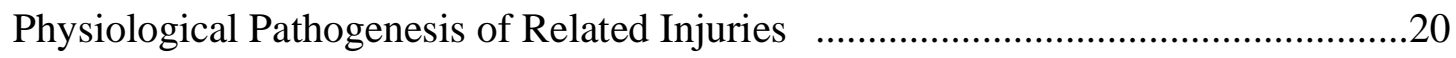

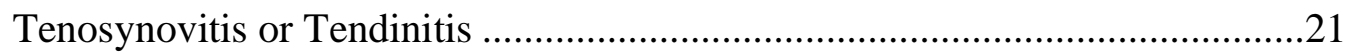

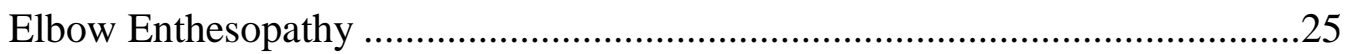

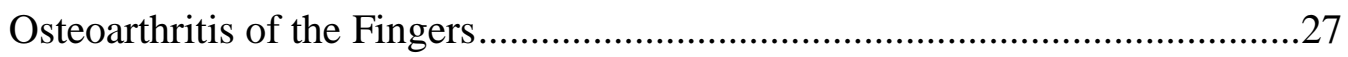

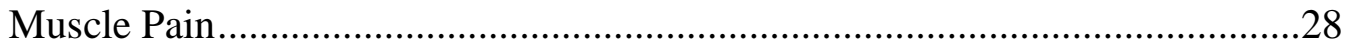

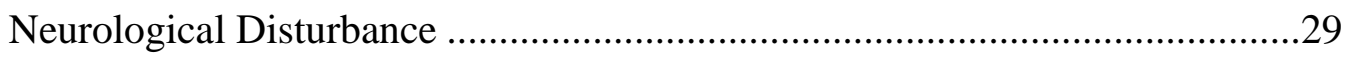

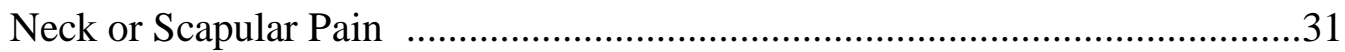

Chapter 3: Causes of Physiological Injury in Piano Playing ....................................33

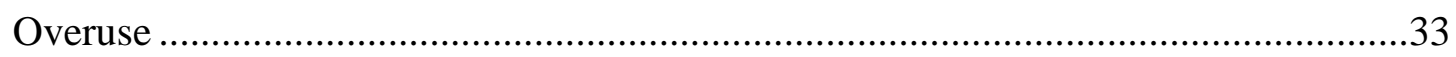

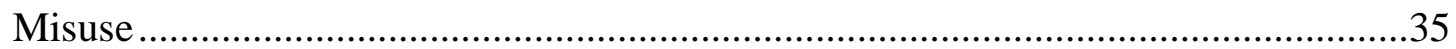

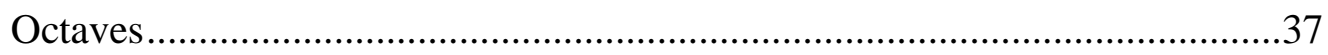

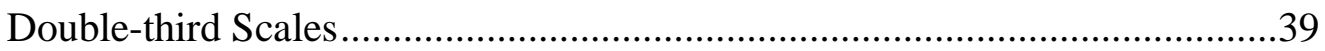

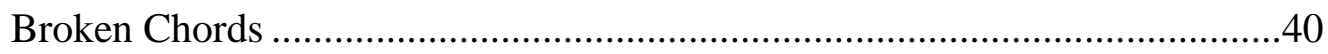

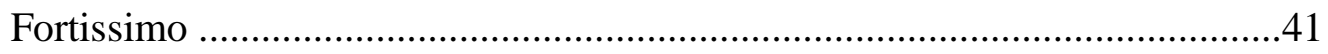

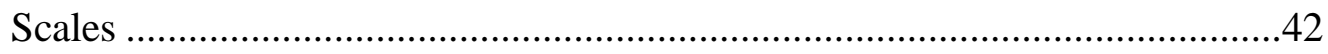

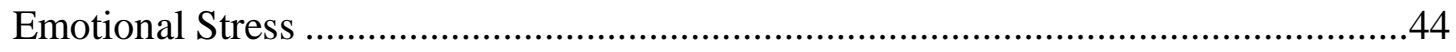

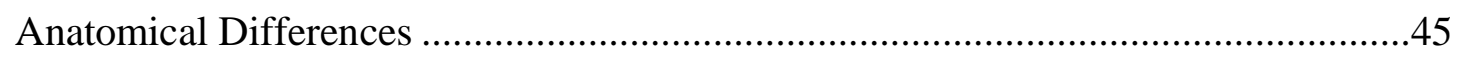

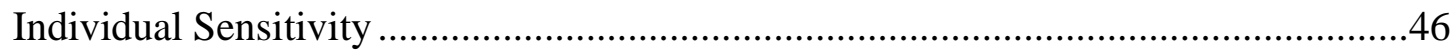

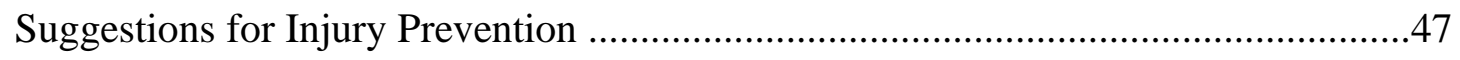

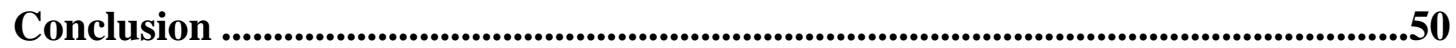

Bibliography ….......................................................................................................................53 


\section{List of Figures}

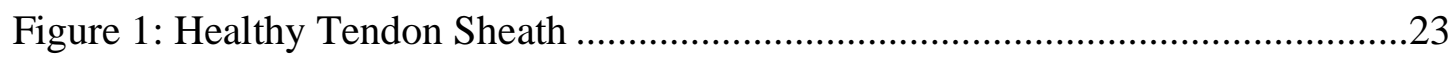

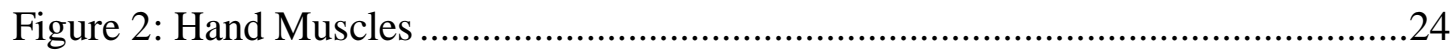

Figure 3: Anatomy of Tennis Elbow and Golfer's Elbow........................................26

Figure 4: Hand Anatomy and Function: Nerve Anatomy ..........................................31 


\section{Chapter 1}

\section{Introduction}

Playing the piano involves nearly constant and often repetitive movements of the fingers, hands, and arms. This fact objectively indicates that, like many athletes, pianists almost inevitably encounter some risk of physiological injury while practicing and

performing. The issue of physiological injury in piano playing has been well documented in developed countries and regions, with a noticeable exception of China. Chinese musical pedagogy exhibits a significant emphasis on the technical components of music performance while frequently ignoring the connection between the physiological structure of the human body and piano playing. To my knowledge, there is no systematic theoretical research in China regarding the problems of physiological injury in piano playing, nor is there an establishment of related specialized clinics for outpatient treatment of piano-related injuries.

In this thesis I explore the issues of physiological injury in piano performance, with a focus on Chinese performance and pedagogy. Research includes accepted piano pedagogy, sports medicine, the science of human physiology, and my own personal experiences in the exploration of injury and injury prevention. Additionally, I propose methods for prevention of injury, with the goal of helping to raise the level of piano playing and lower the probability of encountering injury for pianists of all levels. 
Perhaps the most famous example of physical injury in piano playing is the experience of Robert Schumann (1810-1856), who was forced to abandon his ambition of becoming a professional pianist due to the injury of his hand from overuse. He was eager to develop his technique due to his late exposure to music, adopting unscientific and excessive practice habits to pursue his passion. He even used a mechanical device that he believed would help him develop strength in individual fingers. He experienced serious injury and had to abandon hope of being a performer, lending a bittersweet tinge to the beautiful compositions he subsequently created.1

Some of the world's leading contemporary pianists have also suffered from physical injuries as a result of improper practice. In Jiao Yuanpu's talks with well-known modern pianists, The Colors Between Black and White: Interviews with World Pianists,2 he mentions several pianists who suffered physical injury due to overly stressful playing. He subsequently discusses their injuries, symptoms, and related treatments. For example, the American pianist Leon Fleisher developed symptoms of dystonia in the little finger of his right hand during practice, but he did not pay much attention at the beginning of the injury; he just thought that he needed to work harder. Based on this assumption, he further increased the amount of practice, which eventually led to the weakening of his

1 Eric Sams. "Schumann's Hand Injury." The Musical Times 112, no. 1546 (1971):1156, https:// doi:10.2307/954772.

2 Jiao Yuanpu 焦元溥, Youyi Heibai:Shijie Gangqinjia Fangtan Lu 游艺黑白: 世界 钢琴家访谈录[The Colors Between Black and White: Interview with World Pianists], (Beijing,Shenghuo,Dushu,Xinzhi Sanlian shudian,2010), 3. 
entire right hand. At the height of his performance career, at the age of 37, Fleisher was forced to withdraw from the stage. Many years later, he recovered most of the use of his hand through Botox treatments and could resume a limited schedule of public performances. 3

Similarly, the French pianist Jean-Efflam Bavouzet, who ignored all the warning signs from his body during his playing, practiced octaves feverishly and gradually lost the full extension of his fingers. Finally, his whole body turned to one side. He underwent two years of complete physical therapy to recover from his injuries. Michel Beroff, who is also a famous French pianist, also suffered for seven years from dystonia in his right hand.4

\section{The Virtuoso World in China}

With increasingly fierce social competition and a series of educational policies introduced throughout China in recent years, more and more Chinese parents send their children to professional teachers for piano (and various other classes), to give their children a special skill that helps them advance in their studies and social status. In the process, teachers increasingly are judged by the competition prizes their students win, rather than by their teaching style and their students' general improvement.

3 Jiao, Youyi Heibai, 346.

4 Ibid., 282. 
Many competitions and examinations require specific repertoire, sometimes obliging piano teachers to select works that are beyond their students' current abilities, forcing the students to develop highly specialized skills to meet the requirements. In this situation, students often develop habits of movements which present dangers for their future piano playing that include a combination of unrefined physiological techniques, frequent repetition of high-intensity exercises, and inefficient technical postures.

\section{Personal Experience}

Strong piano execution requires a firm commitment to intensive practice that often includes the repetitive manipulation of many parts of the human body, especially the hands. Excessive practice or use of improper playing techniques and postures may cause physiological injury to the body and can even affect the peripheral nervous system. These effects range from mild discomfort during the performance of a work to noticeable disturbance in the daily life of the individual; it can even cause the end of a playing career.

I myself have experienced a long history of physical injuries due to improper technique. I believe that learning more about relevant medical research, exercise physiology, and other disciplines, combined with exploration of various methods for playing the piano, can make a positive difference in my own life, and that of other 
musicians. I also hope that, through this study, I can gain a better understanding of the physiological injuries that can occur in piano playing. I want to apply rational and scientific principles of practicing, playing, and teaching to reduce the probability of physiological injuries in my own playing and also to help my own students have healthy playing careers.

\section{Research History on Physiological Injury}

The scholarly literature on physiological injury in the process of playing the piano has explored both the physiological structure of the hand and the physiological mechanics of piano technique. Research outside China on physiological problems in music performance is developing vigorously. Many of the skills and ideas that Chinese pianists and piano professors use today in performing, teaching and other activities have evolved through years of careful research and experimentation by foreign experts. On the other hand, emphasis on avoiding physiological injury in music performance lags behind in China; unfortunately, the actual occurrence of injuries is all too real.

Before the study of injuries in musical performance became widespread as an independent research field, early medical scientists conducted research that studied occupational injuries and conditions. Among many such documents is the landmark study

published in 1700 by Bernardino Ramazzini, "De Morbis Artificum Diatriba (Diseases of 
Workers)."s In this treatise, Ramazzini, who is often called the father of occupational medicine, describes in detail the common conditions of miners, masons, potters, printers, weavers, bleachers, jewelers, blacksmiths, gravediggers, farmers, soldiers, surgeons, midwives, nurses, chemists, and more than 50 other professions. At the same time, he was the first medical worker who included the patient's occupation as part of the consulting process leading to the actual medical diagnosis. He concluded that "overwork" is one of the important reasons leading to occupational injury.6 However, during the 18th and early 19th centuries, there was very little specific study of the occupational injuries of musicians and artists. The only available literature was limited in its content, with the result that there is almost no medical evidence documenting occupational conditions of musicians during this time.7

Since the early 20th century, research into musical performance injuries has expanded on a scale that is no longer tied to the symptoms of a similar type of work but is now an independent part of the entire medical study of occupational injuries. Studies began to use more scientific and rigorous experimental means to carry out detailed physiological research among musicians. This has led to the emergence of new research literature on musical performance injury, which has been an important basis for the active

5 Malcolm H. Pope, "Bernardino Ramazzini: The Father of Occupational Medicine,” Spine 29, no. 20 (2004): p. 2335, https://doi.org/10.1097/01.brs.0000142437.70429.a8).

6 Pope, "Bernardino Ramazzini," 2335.

7 Ibid., 2337. 
research of this topic. Examples include the book Diseases of the Musical Profession: a Systematic Presentation of their Causes, Symptoms and Methods of Treatment, written by German musician and neurologist Kurt Singer, published in 1932;8 and Occupation and Health: Encyclopaedia of Hygiene, Pathology and Social Welfare, published in 1930.9

These and other sources dedicate entire books or independent chapters to describing detailed scientific research on music performance injuries.

Based on the efforts of these and other predecessors, many scientists now study and treat the problems of physiological injury caused by music performance, attracting significant attention in developed countries and regions around the world. There are already dozens of rehabilitation centers for performing artists in the United States, such as the Johns Hopkins Performing Arts Rehabilitation Program, 10 NovaCare Performing Arts Rehabilitation,11 and Performing Artist Athletes Program at Boston Children's

8 Kurt Singer and Wladimir Lakond, Diseases of the Musical Profession: a Systematic Presentation of Their Causes, Symptoms and Methods of Treatment (New York:

Greenberg, 1932).

9 Occupation and Health: Encyclopaedia of Hygiene, Pathology and Social Welfare (Geneva: International Labour Office, 1930).

10 "Rehabilitation for Performing Artists: Johns Hopkins Physical Medicine and Rehabilitation," Rehabilitation for Performing Artists | Johns Hopkins Physical Medicine and Rehabilitation, February 17, 2020, https://www.hopkinsmedicine.org/physical_medicine_rehabilitation/services/programs/pe rforming-arts-rehab.html).

11 "Performing Arts Rehabilitation| NovaCare," accessed April 27, 2020, https://www.novacare.com/services/sports-medicine/performing-arts-rehabilitation/). 
Hospital.12 The orthopedic surgery clinic at the Tokyo Women's Medical University's Affiliated Mountain Hospital has studied and diagnosed music performance injuries for more than 30 years.13 Taiwan's Rongmin Hospital in Taipei has set up a "Special Outpatient Clinic for Performing Arts Injury" to specialize in the research and treatment of performance injuries in Taiwan.14

\section{Literature Review in China}

To investigate these topics, I searched databases and school libraries in China, finding that the existing literature on the issue of physiological injury in piano playing is based primarily on methods for playing the piano; however, there are scarcely any interdisciplinary and comprehensive studies linking piano playing with human physiology and sports medicine. Current literature falls into two broad categories: methods for practice and performance, and studies of piano majors and their teachers.

12 "Performing Artist Athletes Program: Boston Children's Hospital," Boston Childrens Hospital, accessed April 27, 2020, http://www.childrenshospital.org/centers-andservices/programs/o-_-z/performing-artist-athletes-program\#).

13 Foreign Musicians 音楽家外来 | 東京女子医科大学整形外科, accessed April 27, 2020 , http://www.twmu.ac.jp/TWMU/Medicine/RinshoKouza/061/musician_foreign.html). 14 Peng Jiju 彭基巨, “Gangqin Yanzou Yundong Shanghai de Yuanyin jiqi Fangfan”钢 琴演奏运动伤害的原因及其防范 [Causes and Prevention of Sports Injuries in Piano Playing], Hunan Shifan Daxue 湖南师范大学(2006):23. The title for this and subsequent Chinese-language sources trans. Ruixi Niu. 
The first category focuses on how to perform various musical passages, emphasizing that correct playing and practicing methods benefit the performance of musical works and protect the pianist's physiological functions. For example, Fan Hexin's thesis, “Common Sports Injuries and Protections in Piano Teaching and Performance" 15 uses the piano performance method as an entry point to discuss the causes of physiological injuries in piano performance. The related prevention methods are expounded from the perspective of teaching activities and practice methods.

Students and teachers in music performance majors are the main subjects in the second category. Through the collection of data to document the prevalence of music performance injury, studies emphasize that the learning process should be mindful of the understanding and application of human physiological science. For example, in the investigation report of Preliminary Report on the Investigation of Professional Injury among Music Students, 16 Peng Yiwen, an attending physician in the Department of

15 Fan Hexin 㚞禾心, “Gangqin Jiaoxue yu Yanzouzhong Changjiande Yundongchuangshang yu Fanghu” 钢琴教学与演奏中常见的运动创伤与防护 [Common Sports Injuries and Protections in Piano Teaching and Performance], Gangqin Jiaoxue Lun 钢琴教学论 [On Piano Teaching], (Shanghai: Shanghai Yinyue Chubanshe, 2008),132. The title for this and subsequent Chinese-language sources trans. Ruixi Niu.

16 Peng Yiwen 彭薏雯, “Dazhuan Yinyuexi Xuesheng Zhuanye Shanghai zhi Diaocha Chubu Baogao” 大专音乐系学生专业伤害之调查 — 初步报告 [Preliminary Report on the Investigation of Professional Injury among Music Students], Zhonghua Fujian Yixue Zazhi 中华复健医学杂志(1994):105-108. The title for this and subsequent Chinese-language sources trans. Ruixi Niu. 
Rehabilitation Medicine, Veterans General Hospital, Taiwan, shows the proportion of students who have physical injury due to harmful practice gestures.

In the thesis "The Causes and Prevention of Piano Performance Injury,"17 Peng Jiju focuses on piano playing, starting with posture and the movement characteristics of hand and shoulder. His paper describes the importance and necessity of preventing physiological and psychological injuries in piano playing; it also advances the tentative idea of effective prevention and treatment of musical performance injuries from a social level. In Shen Xuan's dissertation, “Investigation on Physiological Problems in Piano Performance Techniques,"18 she analyzes the movement principles of human organs, nervous system, and sensory organs that occur while one plays and practices the piano, and then proposes a method of physiological principles to be followed when playing. Huo Shuzhen, Zhou Qiuyun, and Gao Xiuzhi's thesis, “Analysis of the Prevention and Treatment of Special Common Diseases in Art Colleges,"19 primarily focuses on data

17 Peng Jiju 彭基巨, “Gangqin Yanzou Yundong Shanghai de Yuanyin jiqi Fangfan”钢 琴演奏运动伤害的原因及其防范 [Causes and Prevention of Sports Injuries in Piano Playing], Hunan Shifan Daxue 湖南师范大学(2006):23. The title for this and subsequent Chinese-language sources trans. Ruixi Niu. 18 Shen Xuan 谌萱, “Gangqin Yanzou Jishuzhong de Shengli Wenti Yanjiu” 钢琴演奏 技术中的生理问题探究[Investigation on Physiological Problems in Piano Performance Techniques], Hunan Shifan Daxue 湖南师范大学 (2006): 43. The title for this and subsequent Chinese-language sources trans. Ruixi Niu.

19 Huo Shuzhen 霍淑珍, Zhou Qiuyun 周秋云, and Gao Xiuzhi 高秀芝, “Yishu Yuanxiao Teshu Changjianbing de Fangzhi Xiaoguo Fenxi” 艺术院校特殊常见病的防 治效果分析 [Analysis of the Prevention and Treatment of Special Common Diseases in Art Colleges], Zhongguo Xiaoyi 中国校医 （1993）：6-8. The title for this and subsequent Chinese-language sources trans. Ruixi Niu. 
collection and analyzes the occurrence probability and types of physiological disorders in three categories: instrumental music, vocal music, and dance. The article points out the need for scientific knowledge in the arts in order to strengthen the prevention and treatment of related conditions. Cai Yang's article "Avoiding Muscle Injury in the Hand in Piano Skill Training"20 is one of the few comprehensive studies in China that combines multiple perspectives in medicine, physiology and other disciplines. Based on a structural medical analysis of the performer's palm through the questionnaire model, the author explains a variety of methods to avoid muscle damage in piano playing.

In summary, the majority of the related research in China presents data from the perspective of piano performance, while there are relatively fewer scholarly articles, studies, and books that combine medicine and physiology from the perspective of the types, characteristics, and causes of disease. Although the majority of the literature talks about observing the physiological mechanism of the human body in piano playing, it does not discuss in detail the relationship between the piano-playing mechanism and the physiological disorders; thus, the research cannot effectively prove that wrongful practice methods are the root cause of physiological injury in piano playing.

20 Cai Yang 蔡扬, “Gangqin Jiqiao Xunlian Zhong Shoubu de Jineng Sunshang de Bimian”钢琴技巧训练中手部的技能损伤的避免 [Avoiding Muscle Injury in the Hand in Piano Skill Training], Zhongguo Wuhan Yinyue Xueyuan Xuebao 中国武汉音乐学院 学报 (2013): 11-13. The title for this and subsequent Chinese-language sources trans. Ruixi Niu. 


\section{Literature Review Outside of China}

In addition to the limited Chinese resources in the field of performance injury, there are many sources in Western literature, especially in the United States. Valuable information about basic hand and upper-limb anatomy and pathology appears in the book Hand Surgery, by Richard A. Berger and Arnold-Peter C. Weiss, 21 and in the book Hand and Wrist, by James R. Doyle.22 In order to avoid pain, one needs to understand the cause of the pain as it relates to the fundamental structures of the human body that are involved in piano playing. Ian Winspur's The Musician's Hand-A Clinical Guiderz was the first book to focus on the specialized topic of the upper limb and hand in musicians, discussing the conditions that musicians suffer, the assessment and treatment they require, and the importance of preventing injury before it starts.24 This book contains many anecdotal observations by leading musicians and conductors on performance technique that give a fascinating insight into the minds of these gifted individuals. 25

From the point of view of sports medicine, most physiological injuries that occur during the piano-playing process are mainly divided into two categories: acute and

21 Richard A. Berger and Arnold-Peter C. Weiss, Hand Surgery (Philadelphia: Lippincott Williams \& Wilkins, 2004).

22 James R. Doyle, Hand and Wrist, Philadelphia: Lippincott Williams \& Wilkins, (2006).

23 Ian Winspur, The Musicians Hand: a Clinical Guide,London, UK: JP Medical Ltd, (2018).

24 Winspur, The Musicians Hand, 12.

25 Ibid., 12. 
chronic. "Acute" refers to sudden occurrence, for which there will be clear causes and symptoms of the disease. "Chronic" refers to injury caused by small, repeated instances of damage, for which we cannot clearly distinguish the specific time when the symptoms began; yet, when performing certain actions, we will notice discomfort in the tissues. Simply put, the problem is "physical injury caused by overwork." 26 But whether it is "acute" or "chronic" injury, the cause can be attributed to actions in which "physical tissues are damaged due to external forces." 27

The general medical consensus is that most human physiological tissues have a certain ability to heal. As long as the structure is used properly during exercise, in general it will not produce clinical disease reactions. However, if the burden on the tissue exceeds its normal tolerance range, it will cause the self-healing ability of the human body to be compromised and the occurrence of physical injury becomes unavoidable. 28

It is crucial to understand the unique and specialized body movements involved in piano playing if one wishes to connect physiological disorders with the mechanisms of piano playing. Variations in the impact of the risk factors leading to pain may depend on a particular pedagogical school and whether or not its physiological procedures are mechanically efficient. It is quite likely that many orthodox ways of teaching the piano in

26 Doyle, Hand and Wrist, 257.

27 Ibid., 257.

28 Frank W Booth, Christian K Roberts, and Matthew J Laye, "Lack of Exercise Is a Major Cause of Chronic Diseases," Comprehensive Physiology (U.S. National Library of Medicine, April 2012), https://www.ncbi.nlm.nih.gov/pmc/articles/PMC4241367/) 
fact cause pain; however, because of the way in which pain has been individualized,

rationalized, and denied by pianists due to various reasons, that possibility has not been recognized thoroughly within the pedagogical profession.29

Otto Ortmann's The Physiological Mechanics of Piano Techniquezo is a

fundamental work in the literature about the nature of muscular action as used in piano playing and of the effects upon the piano keys and the piano tone. The Musician's Way by Gerald Klickstein 31 is a guide to practice, performance and wellness. In Part III Lifelong Creativity, Klickstein explores the physical aspects of self-care during injuries, analyzes the causes of injury, and discusses warning signs and responses, along with injury-prevention basics. Richard Norris's The Musician's Survival Manual: A Guide to Preventing and Treating Injuries in Instrumentalists, 32 Gyorgy Sandor's On Piano Playing: Motion, Sound and Expression33 and the journal Medical Problems of

29 Robert R. Alford and Andras Szanto, "Orpheus Wounded: The Experience of Pain in the Professional Worlds of the Piano," Theory and Society 25, no. 1 (1996): 23, https://doi.org/10.1007/bf00140757)

30 Otto Ortmann, The Physiological Mechanics of Piano Technique: an Experimental Study of the Nature of Muscular Action as Used in Piano Playing, and of the Effects Thereof upon the Piano Key and the Piano Tone (New York: Da Capo Press, 1981). 31 Gerald Klickstein, The Musician's Way: A Guide to Practice, Performance, and Wellness (Oxford: Oxford University Press, Incorporated, 2009).

32 Richard Norris, The Musician's Survival Manual: A Guide to Preventing and Treating Injuries in Instrumentalists (St. Louis, Mo.: MMB Music, 1993).

33 György Sándor, On Piano Playing: Motion, Sound and Expression (Belmont, CA: Wadsworth/Thomson Learning/Schirmer, 2007). 
Performing Artists, founded by Dr. Alice Brandfonbrener, 34 all provide guidance in discussing rational selections and scientific practice in piano playing.

\section{Anticipated Conclusions}

Based on the research background described above, this thesis aims to achieve the following objectives:

1) To explore the literature and research data about musical performance injury, and to consider both the current research situation and newly developing trends of related investigation.

2) Aided by the related investigation data, to identify the types, symptoms, and reasons for the physiological injuries which may appear in the piano-playing process. Carrying on this discussion involves exploring the relationships among the physiological structures, the related playing skills, and the physiological conditions which can occur.

34 Alice Brandfonbrener, "Joint Laxity and Arm Pain in Musicians," Medical Problems of Performing Artists 15(2) (June 2000): 72-74. 


\section{Chapter 2}

\section{Types of Physiological Injuries in Piano Playing}

Piano performance is a skill-based training that requires players to perform precise operations with their hands, wrists, arms and other body parts over a long period of time. To be safe, these repeated movements must be based on a correct understanding of the science of human physiological structure. Ignorance may lead to the unscientific use of body tissues during training, triggering the possibility of physical damage.

The instrument itself is part of the problem. The craft of building and constructing pianos developed rapidly between 1825 and 1900. Zhou Weimin wrote in his book, The Multidimensional Study of The Art of The Piano, "The structure of the piano's frame evolved from an early wooden frame into a metal frame, which strengthened the piano's ability to withstand the tension of the strings and the pounding of the hammers, and provided the piano with greater support so that it could withstand a more powerful performance. "35 These changes allowed composers to create musical works that required more physical strength, faster speed, and more complex technical requirements from the

\footnotetext{
35 Zhou Weimin 周为民, Gangqin Yishu de Duoweidu Yanjiu 钢琴艺术的多维度研 究 [The Multimensional Study of the Art of the Piano] , (Beijing,Renmin Chubanshe,2011）, 25. The title for this and subsequent Chinese-language sources trans. Ruixi Niu.
} 
pianist. The piano action itself also became heavier, requiring more force to play each key, thus obliging performers to approach the physical limits of their bodies, specifically the muscles and tendons in their arms and hands, in the process of playing the piano.

During this early period, research on pianists' physiological damage during piano playing was mainly focused on "Muscle Non-twitching Treatment" and "Ring Finger Expansion Surgery."36 The "Muscle Non-twitching Treatment" is the earliest research in the medical field mainly for specific occupations such as telegraphers who need to use finger muscles quickly and frequently for a long time.37 In 1887, Poore proposed his new diagnosis of pianist's finger-muscle convulsions. He believed that the causes of injury in musicians were more complicated than for telegraphers and those in other traditional occupations. He labelled pianists as a special category of people who are more prone to the disease. 38

Although not intended as a treatment of finger-muscle convulsions, "Ring Finger Expansion Surgery" is perhaps a symptom of those times. It was invented by American medical scientist William Forbes. In a tendon excision surgery, the common extensor muscle accessory tendon is cut, allowing the ring finger to extend to a greater range. This resulted in pianists having more freedom of motion in their hands to overcome some of

36 G. V. Poore, "Clinical Lecture on Certain Conditions of the Hand and Arm Which Interfere with the Performance of Professional Acts, Especially Piano-Playing," Bmj, $\mathrm{Br}$ Med J. vol. 1, no. 1365, (1887): pp. 441-446, https://doi:10.1136/bmj.1.1365.441).

37 Poore, "Clinical Lecture,"441.

38 Ibid., 441. 
the technically demanding passages that were becoming normalized in piano compositions.39

At the same time, due to the progress of piano manufacturing technology and the increasing difficulty of piano works in this period, various types of piano skill-auxiliary practice equipment, medical surgery and even drugs become widely popular. Scientists began to intensify their studies on using the human hand in piano playing and the relationship between muscle strength and physiological structure, gradually creating a research system. This chapter will examine some of the more common physiological injuries in the piano playing process by using existing research developed by sports medicine and physiology. These injuries will be explored and analyzed according to the type of disease, pathogenesis, and causes.

\section{Types of Injuries}

A survey and interview conducted by Cai Yang, a professor at the School of Music and Dance of Guangzhou university, on piano-based injuries included 496 students and teachers of piano courses in the major music schools and comprehensive universities in China. The survey response was overwhelming: “373 respondents have experienced

39 William S. Forbes, "The Liberating of the Ring Finger in Musicians by Dividing the Accessory Tendons of the Extensor Communis Digitorum Muscle," The Boston Medical and Surgical Journal 111, no. 26 (1884), p. 601, https://doi.org/10.1056/nejm188412251112601). 
hand-muscle energy problems. Fatigue and injuries occurred for $75.2 \%$ of the total respondents." 40 Such a high rate of injury strongly suggests a serious lack of scientific and physiological understanding of proper body movements among young Chinese pianists and their teachers. According to the survey report of Peng Yiwen on the investigation of professional injury among music students in China: for a series of physical injuries in piano performance, the highest proportion of injuries occurred in the wrist (53.2\%), followed by the respective proportions of arm (43.1\%), shoulder (35\%), back (27.7\%), and head and neck (24.1\%).41 Related investigations of physiologicalinjury symptoms during piano playing show that the injury symptoms are mainly soreness, fatigue, swelling and pain. According to a study conducted by Nora Shields and Sara Dockrell in 2000 on the prevalence of injuries among pianists in music schools in Ireland, "Among the 182 respondents from seven participating music schools, pain was

40 Cai Yang 蔡扬, “Gangqin Jiqiao Xunlian Zhong Shoubu de Jineng Sunshang de Bimian”钢琴技巧训练中手部的技能损伤的避免 [Avoiding Muscle Injury in the Hand in Piano Skill Training], Zhongguo Wuhan Yinyиe Хиеуиаn Xиеbao 中国武汉音乐学院 学报 (2013): 11-13. The title for this and subsequent Chinese-language sources trans. Ruixi Niu.

41 Peng Yiwen 彭薏雯,“Dazhuan Yinyuexi Xuesheng Zhuanye Shanghai zhi Diaocha Chubu Baogao”大专音乐系学生专业伤害之调查 — 初步报告 [Preliminary Report on the Investigation of Professional Injury among Music Student], Zhonghua Fujian Yixue Zazhi 中华复健医学杂志(1994):105-108. The title for this and subsequent Chinese-language sources trans. Ruixi Niu. 
the most commonly reported symptom with $36.6 \%$ of the respondents indicating this type of injury." 42

In 2002, Japanese scholar Naotaka Sakai surveyed 200 professional pianists and students who had experienced physical injuries attributed to overuse while playing the piano. Sakai divided the common physiological conditions of pianists into six major categories: 1) Tenosynovitis or Tendinitis; 2) Elbow Enthesopathy; 3) Osteoarthritis of the Fingers; 4) Muscle Pain; 5) Neurological Disturbance; 6) Neck or Scapular Pain.43 All of them fall into the category of Repetitive Strain Injury (RSI), referring to a gradual buildup of damage to muscles, tendons, and nerves from repetitive motions.44 RSI can be divided into two types: isotonic movements (repeating the same motions) and isometric movement (sitting in one position for too long). In the next section, I will elaborate on the manifestations and causes of these RSI conditions according to the six different categories classified based on Sakai's research.

${ }_{42}$ Nora Shields, and Sara Dockrell. "The prevalence of injuries among pianists in music schools in Ireland." Medical Problems of Performing Artists 15, no. 4 (2000): 155+. Gale OneFile: Health and Medicine (accessed May 19, 2020).

43 Naotaka Sakai, "Hand pain attributed to overuse among professional pianists: a study of 200 cases." Medical Problems of Performing Artists 17, no. 4 (2002): 178+. Gale Academic OneFile (accessed June 19, 2020).

44 Hunter J H. Fry, "Overuse syndrome of the upper limb in musicians." The Medical Journal of Australia 144.4 (1986): 182. 


\section{Physiological Pathogenesis of Related Injuries}

\section{(1) Tenosynovitis or Tendonitis (also spelled Tendinitis)}

Tendons play an important role in a movement by transmitting the contraction

force produced by the muscles to the bone they hold; the tendons' contribution to stability of the joints is extremely important. Tendons generally have a very complex structure; they are heavily composed of connective tissue and have a small number of cells and rich extracellular matrix, similar to other connective tissue structures. The tendons are mainly composed of three parts: the tendon itself, the muscle-tendon junction, and the bone insertion. 45 The role of the tendon is mainly to attach the skeletal muscle to the bone, so that the skeletal muscle can carry out the synchronous movement of the bone while performing its contracting movement; in this sense, the tendon serves as a "transmission device."

Injury of the tendon refers to the symptoms of inflammation of the tendon and its surrounding tissues. The tendon itself has a certain flexibility, but when excessive fatigue occurs, the tissue fibers will be damaged after it exceeds its physiological elastic accommodation range. Therefore, injury of the tendon is caused by excessive use of

45 Tao Quan 陶泉, Shoubu Sunshang Kangfu 手部损伤康复 [Hand Injury Rehabilitation], excerpt trans. Ruixi Niu, (Shangha:i Jiaotong Daxue Chubanshe, 2006), 126. The title for this and subsequent Chinese-language sources trans. Ruixi Niu. 
muscle fibers and strong repeated pulling, which creates a type of chronic injury to physiological tissues.

Inflammation of the tendon is called Tendonitis (also spelled Tendinitis), while inflammation of the tendon sheath is called Tenosynovitis.46 The most common pathological inflammation point of the tendon site is the location of the tendon sheath, which normally has enough space to allow the tendon to move back and forth as your fingers move47 (see Fig. 1). When a patient has tenosynovitis (swelling of a tendon), tendons move less freely within the sheath, because of increased friction. Tenosynovitis or Tendonitis can be generally divided into the three following types: Stenosing Tenosynovitis at the Radial Styloid Process (De Quervain's Disease), Extensor Carpi Ulnaris Tendinitis (ECU Tendinitis), and Finger Flexor Tenosynovitis.48

46 Mel Winters, “Tendon Problems,” The Islander (The Islander, December 13, 2017), http://theislander.net/tendon-problems/.

47 Ibid.

48 Tao Quan, Shoubu Sunshang Kangfu,128. 


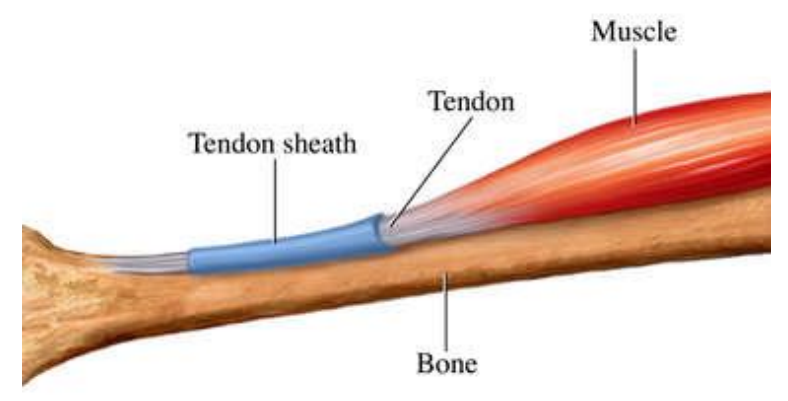

Fig. 1: Healthy Tendon Sheath. Created by Nucleus. From Nucleus Medical Media. https://hlp.nucleushealth.com/healthy-tendon-sheath/view-item?ItemID=445449.

\section{Stenosing Tenosynovitis at the Radial Styloid Process (also called De}

Quervain's Tendinitis or Mommy Thumb): This disease occurs at the tendon sheath of the extensor pollicis brevis and abductor pollicis longus.50 (See Fig. 2 below.) The pathological reason is that the thumb or wrist movement is too frequent, which causes the extensor pollicis longus and the abductor pollicis longus to rub against each other in the tendon sheath of the radial styloid process for a long time. Inflammation, local exudation, edema, and fibrosis cause the sheath wall to become thicker; the tendon also thickens locally, causing the tendon to slide less freely in the tendon sheath, leading to clinical symptoms.51 Patients with De Quervain's Tendinitis may notice pain and swelling near

49 Nucleus, n.d., https://hlp.nucleushealth.com/healthy-tendon-sheath/viewitem?ItemID $=4454$.

50 Ibid.

51 Tao Quan, Shoubu Sunshang Kangfu, 129. 
the base of the thumb, difficulty moving the thumb and wrist (especially when grasping or pinching), sharp pain in the wrist, and pain that spreads further into the thumb or

forearm. 52

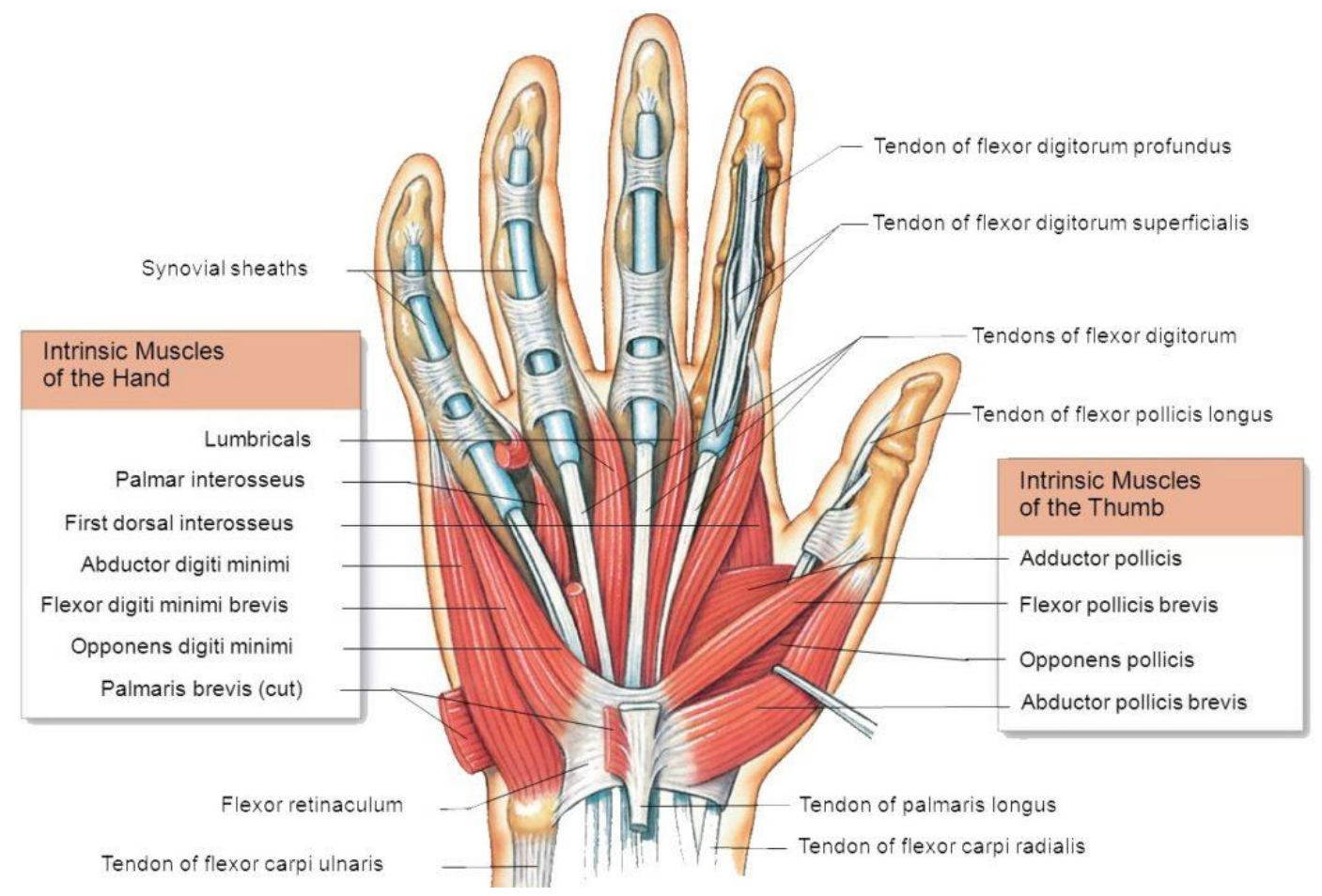

Fig. 2: Hand Muscles. From Anatomy Info. https://anatomyinfo.com/hand-muscles/53.

Extensor Carpi Ulnaris Tendinitis (also called ECU Tendinitis): The pathogenesis of ECU Tendinitis is similar to the De Quervain's Tendinitis described above, where the extensor carpi ulnaris muscle becomes inflamed and irritated. This muscle extends from the outer portion of the forearm and attaches to the fifth metacarpal,

52 “De Quervains Tendinitis New York City, NY," HandSport Surgery Institute, February 17, 2020, https://handsurgeonsnyc.com/de-quervains-tendinitis-mommy-thumb. 53 "Hand Muscles: Attachment, Nerve Supply \& Action," Anatomy Info, October 28, 2019, https://anatomyinfo.com/hand-muscles/. 
functioning to extend the wrist towards the pinky. The biggest difference between ECU

Tendinitis and De Quervain's Tendinitis is the location of the disease. De Quervain's

Tendinitis is located on the radial styloid process on the side of the thumb, while the ECU

Tendinitis is located on the opposite side of the little finger ulnar styloid process54 (see

Fig. 2).

Finger Flexor Tenosynovitis, commonly known as "snapping fingers" or

"trigger fingers": This issue usually appears on the thumb, middle finger, and ring finger.55 The cause of its pathology is closely related to strain, that is, long-term excessive flexion and extension of the fingers resulting in inflammation of the tendon sheath tissue and triggering the thickening of the tendon sheath and narrowing of the sheath. The main manifestation is pain, swelling, and stiffness of the patient's fingers during flexion and extension. 56

\section{(2) Elbow Enthesopathy}

Enthesopathy refers to a problem with the attachment of tendons, ligaments or components of a joint onto the bone.57 People who exercise their upper limbs frequently

54 Tao Quan, Shoubu Sunshang Kangfu, 143.

55 Ibid., 150.

56 Ibid., 150.

57 Tao Quan, Shoubu Sunshang Kangfu, 283. 
and intensely over a long period of time may experience pain and stiffness, or difficulty moving the affected joint or area of the body. For pianists, Enthesopathy is more likely to occur in the arms and elbows. Common symptoms are as follows:

\section{Medial Epicondylitis, commonly referred to as "Golfer's Elbow": A}

tendinous overload injury that causes pain and discomfort on the inner side of

elbow58(see Fig. 3). The pathological reason is that the repetitive use of the wrist and hand causes tears and degeneration of the affected tendons attached to the medial epicondyle; these weakened tendon structures cause pain.59
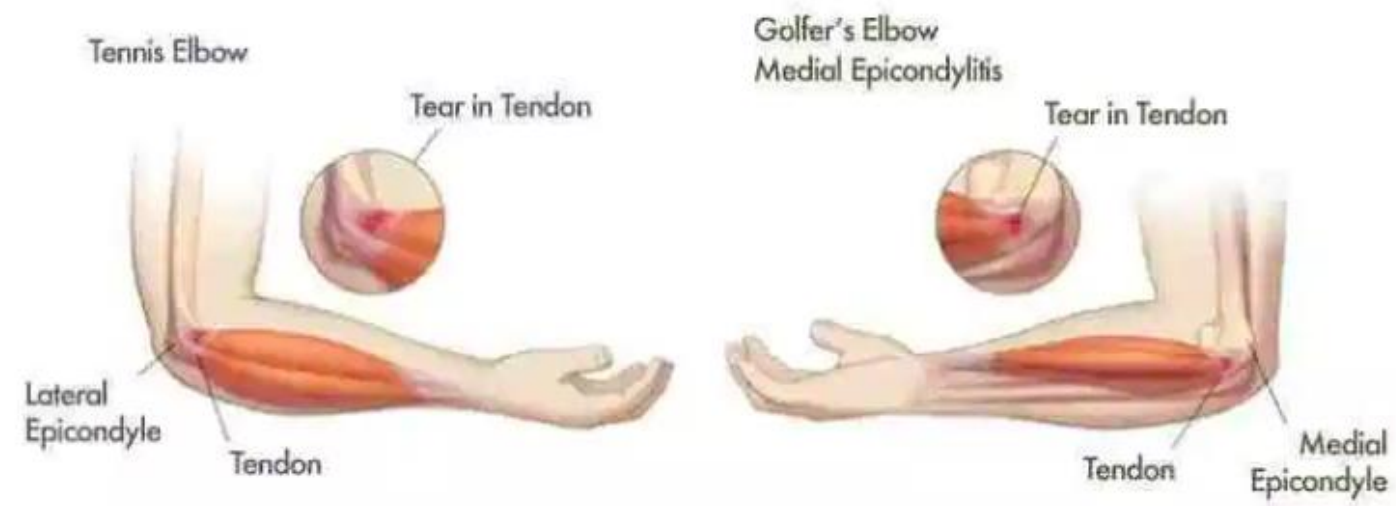

Fig. 3: Anatomy of Tennis Elbow and Golfer's Elbow. From dtap Clinic.

https://www.dtapclinic.com/family-medicine/tennis-elbow/.60

58 Ibid., 303.

59 Ibid., 303.

60 Tennis Elbow and Golfer's Elbow, n.d., https://www.dtapclinic.com/familymedicine/tennis-elbow/. 


\section{Lateral Epicondylitis, commonly referred to as "Tennis Elbow": A}

tendinous overload injury that causes pain and discomfort on the outer side of the elbow61 (see Fig. 3). The pathological reason is mainly due to the excessive contraction and tension of the extensor tendons of the forearm when grasping. Excessive use of the muscle at this location is likely to cause the tendon of these muscle tissues to degenerate and tear.62 In the early stage of the disease, the patient will feel pain on the outside of the elbow joint, which can be relieved after proper rest. However, after the disease deepens, there will be long-term persistent pain and discomfort; this injury can ultimately result in the inability to perform finger extensions and other actions naturally.63

\section{(3) Osteoarthritis of the Fingers}

Arthritis, which literally means "joint inflammation," can affect any joint in the body, including the joints between the 29 bones of the wrist, hand and finger.64 Arthritis of the hand can be painful enough to prevent one from doing even commonplace tasks and chores with their hands. One of the most common forms of arthritis in the hand is Osteoarthritis, which involves wearing away of the smooth cartilage that normally covers

61 Tao Quan, Shoubu Sunshang Kangfu, 308.

62 Ibid., 308.

63 Ibid., 308.

64 James R. Doyle, Hand and Wrist, 87. 
the ends of the bones in a joint.65 This leaves behind a rough joint surface, which can cause pain and swelling due to surface grinding and the body's own inflammatory response. The three most common sites where arthritis occurs in the hand are: at the base of the thumb, where the thumb and wrist come together (the trapeziometacarpal or basilar joint); at the joint closest to the fingertip (the distal interphalangeal or DIP joint); or at the middle joint of a finger.66 All forms of hand arthritis can cause stiffness, swelling, pain, and deformity. 67

\section{(4) Muscle Pain}

Muscle pain is the most likely physical injury among all forms of exercise, and it is also divided into two categories: acute and chronic.68 Acute muscle pain refers to the temporary lack of blood supply to the muscle tissue after the muscle tissue has experienced intense or prolonged exercise. It can also be regarded as muscle spasm and usually subsides after the exercise activity is terminated. Chronic symptoms, on the other hand, mainly refer to the gradual deterioration of the muscle's self-recovery ability, following repeated excessive stimulation of the muscle tissue. If the muscle cannot heal

65 Ibid., 87.

66 Ibid., 88.

67 Ibid., 88.

68 Tao Quan, Shoubu Sunshang Kangfu, 132. 
itself, without prompt treatment the symptoms will persist and muscle tone will show a marked decline. 69

Hand strain is a stretching and tear in a muscle, causing swelling and pain. Strain often occurs in intrinsic muscles of the hand, located within the hand itself, where the thenar muscles are responsible for the fine movement of the thumb, the hypothenar muscles support the fundamental function of the little finger, and the interossei muscles located between the metacarpals assist the lumbricals in flexion and extension (see fig. 2). 70

\section{(5) Neurological Disturbance}

"Neurological disturbance" refers to condition that affect the brain and the central and autonomic nervous systems. It can affect pianists in three major forms: Focal Dystonia, Cubital Tunnel Syndrome, and Carpal Tunnel Syndrome.71

Focal Dystonia72 is a neurological disorder that involves involuntary spasms in small muscles in the body. It can result from overuse or repetitive stress and tends to

69 Ibid., 132.

70 "Muscles of the Hand," TeachMeAnatomy, accessed June 21, 2020, https://teachmeanatomy.info/upper-limb/muscles/hand/.

71 Naotaka Sakai, "Hand pain attributed to overuse among professional pianists: a study of 200 cases.": 178.

72 Dystonia is a neurological disorder that causes excessive, involuntary muscle contractions. 
affect musicians.73 The disorder can afflict the hands, causing the fingers to curl into the palm or extend outward without control. The early symptoms may include a loss of precision in muscle coordination. The repetitive use of a muscle may lead to trembling and cramping pains. 74

Cubital Tunnel Syndrome occurs when the ulnar nerve that crosses the bony groove on the inside of the elbow is compressed or irritated. The groove of the nerves is covered by ligaments, which may become too tight to allow room for the nerves. In some people, the ulnar nerve is unstable and can be moved out of its groove and up and down the bone inside the elbow, which can also cause neural irritation75 (see Fig. 4). Numbness and tingling in the little finger and sometimes the ring finger are common symptoms, because the ulnar nerve provides sensation to this part of the hand.76

Carpal Tunnel Syndrome is a condition when the median nerve is compressed in the wrist.77 The median nerve (see fig. 4), one of the three major nerves in the arm and hand, provides sensation to the thumb, index finger, middle finger and half of the ring finger. The median nerve also controls certain movements of the thumb and fingers. 78

73 N. S. Gordon, "Focal Dystonia, with Special Reference to Writer's Cramp," International Journal of Clinical Practice 59, no. 9 (2005): pp. 1088-1090, https://doi.org/10.1111/j.1742-1241.2005.00603.x, 1088.

74 Gordon, "Focal Dystonia", 1089.

75 Doyle, Hand and Wrist, 412.

76 Ibid., 412.

77 Ibid., 440.

78 Ibid., 440. 
This vital nerve passes through the carpal tunnel, a space covered by a transverse carpal

ligament. In this space, along with the median nerve, are the flexor tendons that allow the fingers to bend. When these flexor tendons thicken and take up too much space in the carpal tunnel, Carpal Tunnel Syndrome can occur, leading to compression of the median nerve.79 Numbness or tingling in the thumb, index finger, middle finger, and possibly the ring and little fingers are the hallmarks of Carpal Tunnel Syndrome.80 Severe Carpal Tunnel Syndrome leads to weakness of the hand due to the loss of hand-muscle strength, especially the thumb.

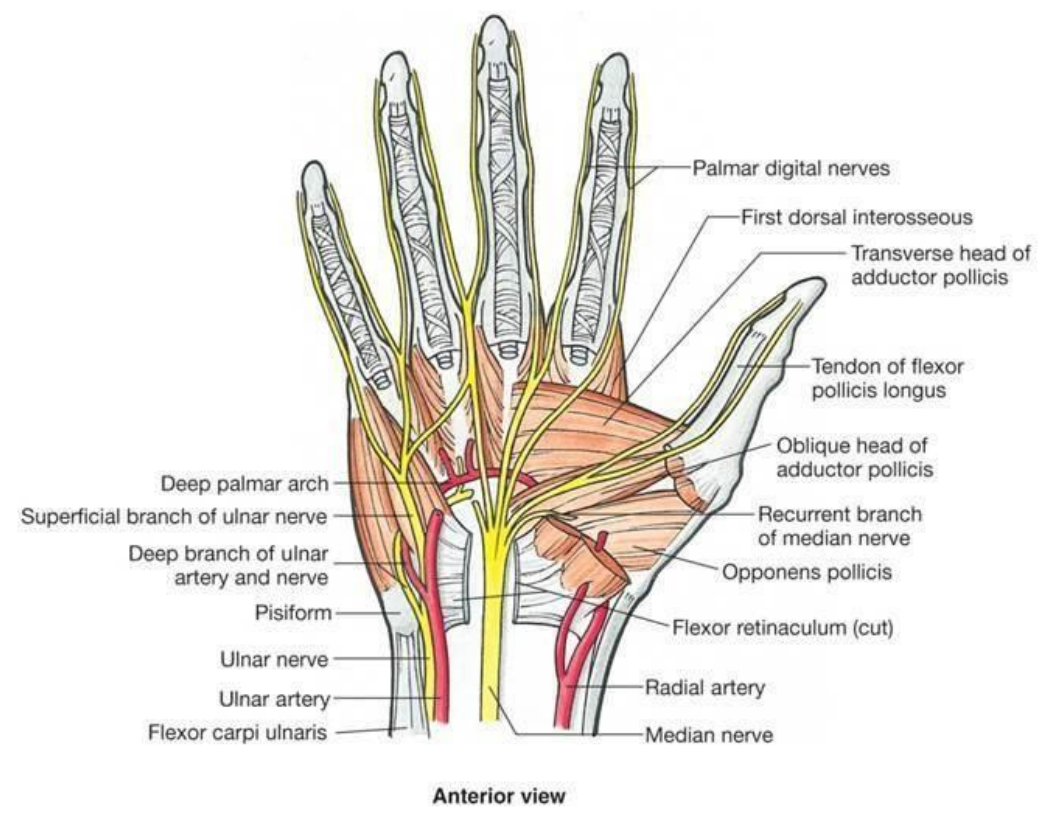

Fig. 4: Hand Anatomy and Function: Nerve Anatomy.

https://www.pinterest.com/pin/574912708673625579/?autologin=true.

79 Ibid., 441.

80 Ibid., 441. 


\section{(6) Neck or Scapular Pain}

Pain and discomfort in the shoulder and neck are mostly caused by mechanical strain injuries created by maintaining the same sitting posture for a long time. 81 The cervical spine of the human body is composed of seven vertebral bodies, and the cervical spine has a certain degree of flexibility. Sitting at a desk (or piano) with bowed posture alters the natural physiological curvature of the shoulder and neck position, resulting in local muscle stiffness and abnormal blood flow. 82

\section{Cervical Radiculopathy, commonly called a "pinched nerve," occurs when a}

nerve in the neck is compressed or irritated at the point where it branches away from the spinal cord.83 This can cause pain or tingling to spread to the shoulders, as well as muscle weakness and numbness along the arms and into the hands.

81 Tao Quan, Shoubu Sunshang Kangfu, 105.

82 Tao Quan, Shoubu Sunshang Kangfu, 106.

83 Ibid., 106. 


\section{Chapter 3}

\section{Causes of Physiological Injury in Piano Playing}

From the pianist's point of view, causes of physiological injury due to piano playing are unique and vary from person to person. However, the primary causes of piano-related injury that can lead to considerable physical pain fall into five general categories: 1) overuse, 2) misuse, 3) emotional stress, 4) anatomical differences, and 5) individual sensitivity. 84

\section{(1) Overuse}

The body has limits. When a pianist overplays beyond what their body will tolerate, fragile tissue can tear apart, leading to injury. Overuse can affect muscles, tendons, and nerves. A sudden increase in playing time or a decrease in rest time can cause wear and tear and can lead to injury. With an understanding of how overuse can cause performance injury, one can improve the chances of staying within safe limits.

Muscles can do only a limited amount of work before they have to rest.

Microscopic tears occur when a muscle is overused through constant or intense exercise.

84 Klickstein, The Musician's Way, 231. 
Minor injuries may heal overnight, but they are often aggravated when the injury is beyond the body's ability to repair quickly. If the pianist continues to use taut muscles, their pain (and injury) will worsen. Serious injury with the possibility of an extremely long recovery period may be required if one continues to practice without allowing the muscles to heal themselves. 85

Overuse can also damage tendons and their sheaths. Emil Pascarelli, a physician, explains that the fluid which lubricates the tendons is depleted by exercise and replenished with rest.86 When a pianist plays non-stop, the fluid may deplete, causing friction between the tendon and sheath. Such abrasions can damage cells, which in turn can cause pain and swelling. Chronic pain can occur if the pianist continues to overuse a tendon and sheath. In addition, the area in which the tendon joins the bone or muscle is particularly vulnerable - tennis elbow is a common manifestation. Inflammation of the tendon causes tendonitis and swelling of the tendon sheath causes tenosynovitis.

When a tendon or sheath is damaged because of overuse, the nerve will also be affected. The most common neurological problem among pianists occurs when nerves are affected by swelling of adjacent tissue. For example, inflammation of the tendinous sheath of the wrist can compress the nerves, causing pain, tingling, and weakness in the hands, common symptoms of carpal-tunnel syndrome.

85 Klickstein, The Musician's Way, 235.

86 Ibid., 237. 
Although the cause is not entirely clear, women pianists suffer significantly more

from overuse injuries than men. As researchers suggest, in general, women are more susceptible to injury because of their smaller body size and hand size, greater joint flexibility, and smaller muscle mass. 87

\section{(2) Misuse}

Misuse occurs when pianists adopt movements or postures that are contrary to the nature of the body. Ans Samama has observed that pain in the upper extremity joints is usually caused by an incorrect work distribution between postural support, balancing muscles, and exercise muscles.88 For example, if a pianist slouches while playing, their poor posture can exacerbate back and neck pain. However, pianists who practice "good use" develop awareness of exercise habits - they adopt balanced postures to avoid excessive muscle tension. This results in an ease of playing and reduced chance of injury. On the other hand, pianists who practice with clenched muscles and twisted joints can damage both their health and their effectiveness as performers. When abusive stress is combined with excessive repetition, pianists often suffer from repetitive strain injuries (RSI), which usually involve the hands, arms, back, and neck.

87 Wilham Newman, The Pianist's Problems (New York: Harper and Bros., 1956), 33. 88 Ans Samama, "Posture and Movement in Making Music," in Current Research in Arts Medicine, ed. Fadi Bejjani (Chicago: A Cappella, 1993): 328. 
In combination with traditional Chinese piano pedagogy, misuse can be found in finger movements and general technique. Fingers are the parts of the human body that are in direct contact with the keys; misuse of finger movements in piano playing can easily cause physical harm. In the application of fingerings, especially in pieces that require moving the fingers quickly in order to accomplish specific running passages, ignoring the importance of rational fingerings can lead to excessive finger movements and unnecessary finger crossings. It can also cause the brevis of the hand to repeat actions continuously, which is very likely to cause these muscle tissues to sustain physical damage due to excessive flexion and extension, especially at the joints of the metacarpal bone of the fingers.

From the perspectives of physiology and personal observation of piano playing and teaching, current trends in piano pedagogy throughout major parts of China still emphasize simple finger-lifting exercises, with the goal of gaining extreme finger independence in playing. This "high-finger" technique requires pianists to keep a fixed position of the arm and wrists while lifting and curling the fingers, often exceeding a comfortable range of motion. This movement repeats at every single strike of the key. Emphasizing the simple tapping force of the finger neglects in inefficient and dangerous ways the anatomical and scientific analysis of body function.

Curling the fingers requires contraction of the flexor muscles, which are on the lower side of the forearm, while lifting the fingers requires contraction of the extensor 
muscles, which are on the top of the forearm. When one set of muscles contracts, the opposite set needs to release to ease the movement; typically, this happens automatically. But if the opposite set contracts at the same time, co-contraction will happen, which directly causes tension, fatigue, and risk of injury. A pianist who lifts a finger higher than necessary not only wastes time without changing the sound to be produced, but also puts excess stress on the tendons and joints.

Technical misunderstanding of difficult contents in piano playing can be the direct cause of physical injury. In order to avoid harmful playing, one must understand the physiological impact on the upper limbs caused by specific techniques, including octaves, double-third scales, broken chords, fortissimo, and running scales.

\section{Octaves}

Octave playing is one of the most dangerous piano techniques, due to its rigid physiological requirements for the hand. The size and flexibility of the hand determines the ultimate horizontal reach for any pianist. Individuals with smaller hands or limited flexibility often encounter difficulty with octave passages, resulting in the temptation to force high-intensity practice that can misuse many of the technical principles discussed in this paper. Misinformed pedagogy and a well-intentioned desire to work harder on this specific technique can easily put a performer at extremely high risk of physical injury. 
From a physiological point of view, the octave hand position requires pianists to contract the extensor muscles of the thumb and little finger continuously, to maintain an expanded hand position. In this state of expansion, the muscles of the back of the hand join the forearm muscles in maintaining constant tension. After a certain duration of octave playing, pianists will almost inevitably feel tired and sore in the hand and arm; this is especially true for pianists with a small hand size. When these symptoms appear, one might imagine that it is due to insufficient strength and endurance, to be remedied not by rest but by more practice. In fact, the pain occurs because of the prolonged tightness of the extensor muscle tissue, resulting in ischemia and fatigue. Muscle fatigue can be defined as exercise-induced decrease in the ability to produce force. This strong sense of tiredness, lack of energy, and feeling of exhaustion relates to the difficulty of performing overwhelming tasks. If the symptoms and discomfort can be relieved shortly after stopping practicing, it means that the acute fatigue was caused by prolonged playing and one needs to take appropriate rest. And if there are various degrees of pain and a persistent tiredness in the muscle tissue, it means that the self-healing ability of the body tissue has been damaged, leading towards a state of chronic muscle fatigue.

For pianists who have difficulty playing octaves freely, it is customary to use the mutual clamping of the thenar and hypothenar muscles in order to make the thumb and little finger stand on the key. As the tension of this technique on the hands is increased, the exercise intensity of the palm muscle is greater, and the flexor and abductor muscles 
will be excessively pinned to the wrist, making it impossible to relax. Excessively practicing octaves can result in wrist deformities. The excessive raising and lowering of the wrist prevents the shoulders, arms, and hands from moving as a whole unit and hinders the weight transmission from finger to finger. If the majority of the force continues to stay within the extensor tendons of the forearm, the pianist will be at high risk for contracting Tennis Elbow.

\section{Double-third Scales}

The general fingering pattern for playing double-third scales alternates

fingerings between 1-3 and 2-4, and in some cases, 2-4, and 3-5. Due to the limitation of finger length, pianists should also try to reach black keys with long fingers and use the upper arm to provide direction for double-third scales. The combination 1-5 and 2-3 is often the most ideal fingering for double-third combinations, especially for double-third trills; longer fingers take black keys and shorter fingers take white keys, while the hand stays in a neutral shape. The muscular action within the hand is also much more comfortable than what results from using 1-3 and 2-4.

Physiologically speaking, playing double-third scales requires the palm to maintain a relatively open position throughout the exercise or musical passage. While the hand is receiving strength from horizontal weight of the forearm, the wrist is held in a relatively straightly line to transmit the force of the forearm to the fingers, rebounding 
slightly as each third is depressed. The upper arm provides direction, abducting gradually as the extremes of the keyboard are approached while making forward/backward adjustments to allow for playing of black keys.

Prolonged use of finger lifting in the pursuit of finger independence can easily cause strain on finger extensors, especially in double notes. Ignorance of horizontal weight transition might lead to vertical motion of wrist movement by swinging the wrist up and down constantly, which goes against the lateral motions of the wrist made possible through cooperative actions of both flexor and extensor muscles, leading to injury. 89

\section{Broken Chords}

Pianists generally believe that the execution of broken chords depends directly on the rotation of the forearm. Alfred Cortot (1877-1962) defined the playing of broken chords as a "movement of impulsion," which requires more active participation of the hand than the fingers. 90 Cortot further noted that a "rocking" motion, which is alternating radial and ulnar deviation, can also facilitate playing broken chords, especially when these patterns move up or down the keyboard.91

89 Brenda G. Wristen, "Overuse Injuries and Piano Technique: A Biomechanical Approach" (dissertation, Texas Tech University, 1998), 166. 90 Alfred Cortot, Rational Principles of Pianoforte Technique (New York: Editions Salabert, 1930), 73.

91 Ibid., 85-86. 
Physiologically speaking, forearm rotation refers to the movement of radial

deviation when moving toward the fifth finger and ulnar deviation when moving toward the thumb. This lateral movement is directly related to the size of the hand. Smaller hands require more lateral wrist movement. However, neither the lateral motions of the wrist, nor forearm rotation replaces the need for a firm finger. At the moment of depressing the key, the joints of the finger must be stabilized in order to transmit the motion of the wrist and forearm.92 Failure to transmit the force may lead the forearm muscle tissues to appear hypertrophic and then to form a certain amount of pressure on the nerve, causing soreness and stiffness.

\section{Fortissimo}

The traditional Chinese pedagogical view of playing fortissimo holds that the amount of force delivered by pressure transfer can always be increased by raising the fingers well above the level of the keys and striking each note down as it takes the pressure, while at same time keeping the wrist in a very low position in order to give a better transmission of the pressure of the arm. However, this view mistakenly ignores the fact that fatigue occurs more quickly when extra movement of fingers is involved. Moreover, without proper understanding of the physiological aspects of upper-limb

92 Wristen, “Overuse Injuries and Piano Technique: a Biomechanical Approach", 145. 
movements, pianists tend to achieve a forte sound level by maintaining too much tension in the arm muscles while keeping the wrist joints fixed, which involves abduction of the thumb and little finger in conjunction with stabilized wrist joints.

In his book The Visible and Invisible in Pianoforte Technique, Tobias Matthay warned that stiff wrists and fingers were the outcome of incorrect or impeded muscular action.93 A flexible wrist is needed to avoid extensor forearm and dorsal pain. More importantly, relaxation serves as the requisite element of tone-production, as long as the upper limbs are free when adding necessary downward exertion of the forearm.

\section{Scales}

Scales are one of the most frequently encountered technical skills in piano playing. In Chinese piano pedagogy, scale playing is mainly accomplished by the flexible movement of the finger and palm joints. The supporting point of the force is at the fingertip, which is a concentrated force point characterized by a high lifting motion, followed by a fast downward motion, which many pianists believe helps to achieve great clarity. Zhou Guangren, professor of piano at the Central Conservatory of Music in Beijing, who is a successful piano pedagogue and a respected thinker about piano

93 Matthay. The Visible and the Invisible in Pianoforte Technique, 139. 
technique, still maintains a deep belief in the high-finger technique. In her book, Zhou

Guangren: The Art of Piano Teaching, she states:

I still think high finger technique is useful when it comes to training student's fingers. The high finger technique can make the knuckles flexible and soft. However, the kind of sound and the concept we should have during the training is completely different. I think both kinds of technique are necessary. Especially for beginners, the high-finger technique can train the fingers' strength, independence and flexibility. 94

The danger is that when this finger-independence, muscle-building exercise is constantly repeated, it produces extreme tension and strain in the hand, putting the student at risk for injury.

From a physiological point of view, when approaching scales naturally, the upper arm gradually abducts as the hand approaches the outer reaches of the keyboard, guiding the rest of the arm to ascend and descend. The elbow remains loose and moves with the upper arm. With the wrist in a neutral position to start, the radial and ulnar deviations alternate between the left and right hands as ascending and descending scales approach. Fingers bend gently and naturally, and no force is applied to the key after it has been depressed. The metacarpophalangeal joint is slightly curved to support the arch of the hands and transmit the weight force from the arm.95

94 Dagang Huang, ed., Zhou Guangren: The Art of Piano Teaching, excerpt trans. Ruixi Niu (Beijing: Central Conservatory of Music Press, 2006), 116. 95 Wristen, "Overuse Injuries and Piano Technique: a Biomechanical Approach," 95. 


\section{(3) Emotional stress}

Emotional stress is another factor that can lead to physical injury for performers.

The burdens on the performer can seem endless, especially in a critical environment.

Students face intense pressure from their professors, colleagues, friends, and family in

music schools around the world. While it is natural to have a craving to succeed and do well in classes, competitions, juries, and recitals, the pressure to get these good results can result in extreme criticism (often self-administered), leading to heightened emotional stress. Often, practice time is increased in search of perfection that will never come, leaving the body vulnerable to injury. Performance anxiety is another factor in emotional stress. The fear of performing in front of an audience can certainly affect a person's performance and their playing skills. All these stressors create unnecessary tension throughout the body as well.

Physiologically speaking, when one set of muscles produces force and starts to contract during exercise, the set of related muscles that move the same bone in the opposite direction must be allowed to stretch. But when two opposing groups of muscles are in a state of contraction at the same time, the body will form a countervailing tension in two opposite directions at the same time, inhibiting normal movement and reducing the body's tolerance to the movement. This will ultimately lead to fatigue in a very short period of time while paving the way for future injuries caused by long-term misuse. 


\section{(4) Anatomical differences}

There are two types of anatomical differences that affect injury risk: body size and body structure.96 The hugeness of the piano is not always a comfortable match for a small person, although there are many tiny individuals who are renowned pianists. When there is a mismatch between the player and the piano, especially for pianists with smaller hands, misuse and injury become more probable. Young pianists especially might assume that they need to strain physically to bend the monster to their will. However, unlike other instruments like the violin that are produced in assorted dimensions, there is no such a thing as a smaller or quarter-size piano. When children encounter a giant piano that is much bigger than their hand size, they naturally believe that keys are heavy to play, and have a tendency to use their wrist to depress with greater force.

Body structure is different from body size, with a key difference being the range of motion in the joints. Some pianists might experience hypermobility, sometimes called “double-jointedness," which simply means that they can extend their joints farther than most people. Pianists who have extremely flexible joints often encounter difficulties because they can misuse or overuse certain muscles when trying to stabilize a loose

96 Klickstein, The Musician's Way, 251. 
joint.97 Pianists with hand and arm pain often have overly flexible finger joints, which is a noteworthy risk factor for injury.

\section{(5) Individual Sensitivity}

Human diversity includes not only anatomical differences, but also genetic and other factors that cause practice-related distress. Different types of sensitivity occur in the nervous system, causing performers to lose control of their movements over time.98 For example, when Focal Dystonia occurs, pianists who are afflicted with this condition are found to have uncontrolled muscle contractions in their performances but function normally in other activities. Pianists with Focal Dystonia may involuntarily curl their right ring and fifth fingers when playing keyboard passages. However, pianists often ignore a series of warning signs, such as pain, soreness and numbness, that might occur when playing the piano, if they are not aware of the relevant physiological science. After a series of symptoms occurs, too many players will simply attribute the problem to a "lack of endurance" that results from insufficient practice. Further increasing the volume and intensity of practice can all too quickly lead to serious injury.

97 Ibid., 256.

98 Ibid., 270. 


\section{(6) Suggestions for Injury Prevention}

Many of the chronic injuries related to piano playing develop slowly, often over a period of months or even years, resulting from an extended period of stress. It is also possible for acute injuries to occur if the normal range of functioning of a given body tissue is suddenly exceeded. The most common cause of acute piano-related injury is a sudden increase in the amount and/or intensity of practice. When such troubles occur, most teachers would suggest that students rest the affected area. However, borrowing words attributed to Benjamin Franklin, "An ounce of prevention is worth a pound of cure."

Sitting comfortably at the instrument is an important starting point for achieving effective and healthy practice. When not required for pedaling, both feet should be placed on the floor, in a straight line down from the knees. The spine should be elongated and the pelvis should remain parallel to the floor, requiring a flexible spine. Warming up the muscle tissues is a good safety routine before playing. Doctors have suggested that muscle tissues perform most effectively at $38.5^{\circ}$ Celsius $\left(101.3^{\circ} \mathrm{F}\right)$, although cold hands while playing may indicate that circulation to the hands is not optimal.99 Gently stretching the upper limbs can help to warm up the muscle tissues and increase muscular endurance.

99 Don B. Chaffin, Gunnar B. J. Andersson, and Bernard J. Martin, Occupational Biomechanics (Hoboken, N. J: John Wiley \& Sons Inc., published 2006), 47. 
Practice segments should ideally be divided into segments no longer than 25-30 minutes, with a break of five-ten minutes interposed between segments. The breaks between practice segments will allow muscle tissues to be relieved, by relaxing from a static playing posture. Moreover, taking breaks tends to improve mental concentration. Physically challenging practice sessions should be alternated with less intense practice; in this regard, it is wise to schedule a less demanding day for recovery after a particularly stressful day.

Pianists should seek to develop a technique characterized by coordinated movement, so that forces are distributed throughout the upper limbs rather than localized in the fingers. Avoid pressing on the keys after playing and do not "pull to the bottom of the keys," as doing this causes unnecessary stress on joints and tendons and cannot contribute in any way to sound production.

In order to avoid forearm strains and elbow injuries, be especially careful when playing near the upper and lower extremes of the keyboard. In this position, the upper limb is twisted and easily injured when combined with greater applied force and repetition. Abduct the elbow joint to keep the forearm, wrist and hand aligned, reducing the pressure on the shoulder joint and muscles. Excessive flexing or stretching of the wrist (for example, when playing arpeggios) should be avoided, as well as lowering the wrist below key level, as these movements can lead to increased carpal-tunnel pressure. Moreover, try to use a variety of motions whenever possible, because repetitive motion 
can contribute to injury. Hence, practice segments should be varied: Avoid excessive repetitions of the same musical passages and remember to take breaks.

In general, a well-toned body is less prone to injury. Swimming could be an ideal form of exercise for pianists, as it offers excellent cardiovascular benefits and strength training without straining important muscles. Be cautious when learning a new motion or skill, as we are more vulnerable to injury before we have developed a smoothly coordinated approach to a given task. Pick pieces wisely that suit your body and hand size and your muscular endurance.

Lastly, be honest about what your body tells you. If you suddenly experience acute pain, you should stop playing immediately; also seek medical attention if the pain does not dissipate. For less severe pain, stop practicing until the pain goes away and then gradually and gently resume practicing. 


\section{Conclusion}

As a key factor in piano technique, knowledge of how the physiological mechanism

works is a recent innovation. It was not until the late nineteenth and early twentieth centuries that educators began to study the movements of piano playing from an objective, scientific point of view.

In China, however, performance injuries have rarely been taken seriously until recent years, as Chinese piano teachers have begun to realize that specific exercises carry potential physical dangers. Perhaps the most prominent example of a biomechanically inappropriate piano movement is the traditional high-finger method of seeking finger independence. As mentioned earlier, the strength of the fingers cannot become equal, due to their mechanical design. The independence of the ring finger is particularly limited. The extensor tendons that control the third, fourth, and fifth fingers are interconnected. In addition, the small inner muscles and tendons of the hand are mechanically relatively weak. Since strength and endurance in playing comes primarily from the shoulders, upper arms, and forearms, there is little need for the fingers themselves to gain strength.

Instead, we need to increase the speed and control of our finger movements, rather than seeking by brute force to strengthen the fingers.

Pianists suffer a variety of injuries that may be directly attributable to practice and/or performance. These include muscle injuries, tendonitis, compression of tendons, nerve 
compression, focal dystonia, and a range of other injuries. Such damage is not necessarily caused only by inappropriate techniques. As discussed earlier, genetic predisposition and emotional stress play a certain role in injury development; some people seem to be more vulnerable than others.

However, there are some easily controlled factors associated with the prevention of injury. One of the most important recommendations for injury prevention is to avoid sudden increases in volume or intensity. Other factors include the need to warm the muscles up before practicing and to let them rest and recover after practicing, which can also help to avoid unnecessary soreness and cramps. Dividing practice into segments with breaks interposed between segments, avoiding extreme flexion or extension of the wrist, and using smooth, coordinated motions can all help to increase safety. Moreover, pianists should avoid continuing to exert downward pressure on the key after reaching the bottom of the stroke, as this practice has been shown to cause unnecessary stress on joints and tendons; it is also certain that, once the hammer has already hit the string, whatever we do to the key can no longer influence the sound of that note. Learn to use momentum, including the free force of gravity, to aid in playing.

After all, every human body is slightly different. Apart from these individual differences, however, the way we all function can be explained in essentially the same ways. Therefore, it is possible to arrive at physiological observations that will apply to 
virtually all pianists and contribute to establishing appropriate techniques, so that we can avoid movements that are potentially dangerous, thereby reducing the risk of injury. 


\section{Bibliography}

"A Patient's Guide to Intersection Syndrome." eOrthopod Patient Education. Accessed June 20, 2020. https://www.eorthopod.com/eorthopodV3/index.php?ID=57dd4157f9f946ff9d8c512 ba8a92e6b.https://www.eorthopod.com/eorthopodV3/index.php?ID=57dd4157f9f94 6ff9d8c512ba8a92e6b.

Alford, Robert R., and Andras Szanto. "Orpheus Wounded: The Experience of Pain in the Professional Worlds of the Piano.” Theory and Society 25, no. 1 (1996): 1-44. https://doi.org/10.1007/bf00140757.https://doi.org/10.1007/bf00140757.

Anatomy and Cause of Tennis Elbow and Golfer's Elbow. n.d. Tennis Elbow and Golfer's Elbow. https://www.dtapclinic.com/family-medicine/tenniselbow/.https://www.dtapclinic.com/family-medicine/tennis-elbow/.

Berger, Richard A., and Arnold-Peter C. Weiss. Hand Surgery. Philadelphia: Lippincott Williams \& Wilkins, 2004.

Bird, Howard A. Performing Arts Medicine in Clinical Practice. Cham: Springer International Publishing, 2016.

Booth, Frank W, Christian K Roberts, and Matthew J Laye. "Lack of Exercise Is a Major Cause of Chronic Diseases." Comprehensive Physiology. U.S. National Library of Medicine, April 2012.

https://www.ncbi.nlm.nih.gov/pmc/articles/PMC4241367/.https://www.ncbi.nlm.nih .gov/pmc/articles/PMC4241367/.

Brandfonbrener, Alice. "Joint Laxity and Arm Pain in Musicians." Medical Problems of Performing Artists 15(2) (June 2000): 72-74.

Cai, Yang. “Gangqin Jiqiao Xunlian Zhong Shoubu de Jineng Sunshang de Bimian” 钢 琴技巧训练中手部的技能损伤的避免 [Avoiding Muscle Injury in the Hand in Piano Skill Training]. Zhongguo Wuhan Yinyue Xuеyuan Xuebao 中国武汉音乐学 院学报(2013): 11-13.

Chaffin, Roger, Gabriela Imreh, and Mary Crawford. Practicing Perfection: Memory and Piano Performance. Mahwah, N.J.: Erlbaum, 2002. 
Chaffin, Don B., Gunnar B. J. Andersson, and Bernard J. Martin. Occupational Biomechanics. Hoboken, N. J: John Wiley \& Sons Inc.,Publication, 2006.

Dawson, William J. "Experience with Hand and Upper Extremity Problems in 1,000 Instrumentalists." Medical Problems of Performing Artists 10(4) (December 1995): $128-133$.

“De Quervains Tendinitis New York City, NY.” HandSport Surgery Institute, February 17, 2020. https://handsurgeonsnyc.com/de-quervains-tendinitis-mommythumb/.https://handsurgeonsnyc.com/de-quervains-tendinitis-mommy-thumb/.

Doyle, James R. Hand and Wrist. Philadelphia: Lippincott Williams \& Willkins, 2006.

Klickstein, Gerald. The Musician's Way: A Guide to Practice, Performance, and Wellness. Oxford: Oxford University Press, Incorporated, 2009.

Fan, Hexin 樊禾心. “Gangqin Jiaoxue yu Yanzouzhong Changjiande Yundong Chuangshang yu Fanghu” 钢琴教学与演奏中常见的运动创伤与防护 [Common Sports Injuries and Protections in Piano Teaching and Performance]. Gangqin Jiaoxue Lun 钢琴教学论 [Piano Teaching], 128-145. Shanghai: Shanghai Yinyue Chubanshe, 2008.

Fishbein, Martin, Susan E. Middlestadt, Victor Ottati, Susan Straus, and Alan Ellis. "Medical Problems among ICSOM Musicians: Overview of a National Survey." Medical Problems of Performing Artists 3(1) (March 1988): 1-8.

Foreign Musicians 音楽家外来 | 東京女子医科大学整形外科. Accessed April 27, 2020. http://www.twmu.ac.jp/TWMU/Medicine/RinshoKouza/061/musician_foreign.html.

Forbes, William S. "The Liberating of the Ring Finger in Musicians by Dividing the Accessory Tendons of the Extensor Communis Digitorum Muscle." The Boston Medical and Surgical Journal 111, no. 26 (1884): 601-2. https://doi.org/10.1056/nejm188412251112601.https://doi.org/10.1056/nejm188412 251112601.

Fry, Hunter J H. "Overuse syndrome of the upper limb in musicians." The Medical Journal of Australia 144.4 (1986): 182-185. 
Gordon, N. S. "Focal Dystonia, with Special Reference to Writer's Cramp." International Journal of Clinical Practice 59, no. 9 (2005): 1088-90. https://doi.org/10.1111/j.1742-1241.2005.00603.x.

“Hand Muscles : Attachment, Nerve Supply \& Action.” Anatomy Info, October 28, 2019. https://anatomyinfo.com/hand-muscles/.https://anatomyinfo.com/hand-muscles/.

"Hand Anatomy and Function: Nerve Anatomy, Median Nerve, Ulnar Nerve." Pinterest. Accessed June 20, 2020. https://www.pinterest.com/pin/574912708673625579/?autologin=true.https://www. pinterest.com/pin/574912708673625579/?autologin=true.

Healthy Tendon Sheath. n.d. Nucleus. https://hlp.nucleushealth.com/healthy-tendonsheath/view-item?ItemID=4454.https://hlp.nucleushealth.com/healthy-tendonsheath/view-item?ItemID=4454.

Huo, Shuzhen 霍淑珍, Zhou, Qiuyun 周秋云, and Gao, Xiuzhi 高秀芝. “Yishu Yuanxiao Teshu Changjianbing de Fangzhi Xiaoguo Fenxi”艺术院校特殊常见病 的防治效果分析 [Analysis of the Prevention and Treatment of Special Common Diseases in Art Colleges]. Zhongguo Xiaoyi 中国校医(1993): 6-8.

Jiao, Yuanpu 焦元溥. Youyi Heibai:Shijie Gangqinjia Fangtan Lu 游艺黑白: 世界钢 琴家访谈录 [The Colors Between Black and White: Interview with World Pianists]. Beijing: Shenghuo, Dushu, Xinzhi Sanlian shudian,2010.

Josef Lhevinne. Basic Principles in Pianoforte Playing. (New York: Dover, 1972).

Lowe, Colleen. "Treatment of Tendinitis, Tenosynovitis, and Other Cumulative Trauma Disorders of Musicians Forearms, Wrists, and Hands . . . Restoring Function with Hand Therapy." Journal of Hand Therapy 5, no. 2 (1992): 84-90. https://doi.org/10.1016/s0894-1130(12)80262-6.https://doi.org/10.1016/s0894$1130(12) 80262-6$.

Matthay, Tobias. The Visible and Invisible in Pianoforte Technique: Being a Digest of the Author's Technical Teachings up to Date. London: Oxford University Press, 1988. 
"Muscles of the Hand." TeachMeAnatomy. Accessed June 21, 2020. https://teachmeanatomy.info/upperlimb/muscles/hand/.https://teachmeanatomy.info/upper-limb/muscles/hand/.

Newman, Williamam S. The Pianist's Problems: A Modern Approach To Efficient Practice and Musicianly Performance. 2d ed. New York: Harper and Bros., 1956.

Norris, Richard. The Musician's Survival Manual: A Guide to Preventing and Treating Injuries in Instrumentalists. St. Louis, Mo.: MMB Music, 1993.

Ortmann, Otto. The Physiological Mechanics of Piano Technique: an Experimental Study of the Nature of Muscular Action as Used in Piano Playing, and of the Effects Thereof upon the Piano Key and the Piano Tone. New York: Da Capo Press, 1981.

Parlitz, Dietrich, Thomas Peschel, and Eckart Altenmüller. "Assessment of Dynamic Finger Forces in Pianists: Effects of Training and Expertise." Journal of Biomechanics 31, no. 11 (1998): 1063-67. https://doi.org/10.1016/s00219290(98)00113-4.https://doi.org/10.1016/s0021-9290(98)00113-4.

Pascarelli, Emil, and Deborah Quilter. Repetitive Strain Injury: A Computer User's Guide. New York: John Wiley and Sons, 1994.

Peng, Jiju 彭基巨. “Gangqin Yanzou Yundong Shanghai de Yuanyin jiqi Fangfan” 钢 琴演奏运动伤害的原因及其防范 [Causes and Prevention of Sports Injuries in Piano Playing]. Hunan Shifan Daxue 湖南师范大学(2006): 23-26.

Peng, Yiwen 彭薏雯. “Dazhuan Yinyuexi Xuesheng Zhuanye Shanghai zhi Diaocha Chubu Baogao" 大专音乐系学生专业伤害之调查 — 初步报告 [Preliminary Report on the Investigation of Professional Injury among Music Student]. Zhonghua Fujian Yixue Zazhi 中华复健医学杂志(1994): 105-108.

"Performing Arts Rehabilitation | NovaCare." Accessed April 27, 2020.

https://www.novacare.com/services/sports-medicine/performing-arts-rehabilitation/.

"Performing Artist Athletes Program: Boston Children's Hospital." Boston Childrens Hospital. Accessed April 27, 2020. http://www.childrenshospital.org/centers-andservices/programs/0-_-z/performing-artist-athletesprogram\#.http://www.childrenshospital.org/centers-and-services/programs/o-_z/performing-artist-athletes-program\#. 
Pope, Malcolm H. "Bernardino Ramazzini: The Father of Occupational Medicine." Spine 29, no. 20 (2004): 2335-38. https://doi.org/10.1097/01.brs.0000142437.70429.a8.

Poore, G. V. "Clinical Lecture on Certain Conditions of the Hand and Arm Which Interfere with the Performance of Professional Acts, Especially Piano-Playing." Bmj 1, no. 1365 (1887): 441-44. https://doi.org/10.1136/bmj.1.1365.441.

Quan,Tao 陶泉, Shoubu Sunshang Kangfu 手部损伤康复 [Hand Injury Rehabilitition]. Shangha:i Jiaotong Daxue Chubanshe, 2006.

"Rehabilitation for Performing Artists: Johns Hopkins Physical Medicine and Rehabilitation." Rehabilitation for Performing Artists | Johns Hopkins Physical Medicine and Rehabilitation, February 17, 2020. https://www.hopkinsmedicine.org/physical_medicine_rehabilitation/services/progra ms/performing-artsrehab.html.https://www.hopkinsmedicine.org/physical_medicine_rehabilitation/servi ces/programs/performing-arts-rehab.html.

Rosset i Llobet, Jaume, and George Odam. The Musician's Body: A Maintenance Manual for Peak Performance. London: Ashgate, 2007.

Sakai, Naotaka. "Hand Pain Related to Keyboard Techniques in Pianists." Medical Problems of Performing Artists 7, no. 2 (1992): 63-65.

Sakai, Naotaka and Satoshi Shimawaki. "Measurement of a Number of Indices of Hand and Movement Angles in Pianists with Overuse Syndrome." Journal of Hand Surgery (European Volume) 25 (2010): 494-498.

Sakai, Naotaka, Michael Liu, Fong-Chin Su, Allen Bishop, and Kai-Nan An. "Hand Span and Digital Motion on the Keyboard: Concerns of Overuse Syndrome in Musicians." Journal of Hand Surgery 31A, no. 5 (MayJune 2006): 830-835.

Samama, Ans. "Posture and Movement in Making Music." In Current Research in Arts Medicine, ed. Fadi Bejjani, 327-330. Chicago: A CappeUa, 1993.

Sams, Eric. "Schumann's Hand Injury." The Musical Times 112, no. 1546 (1971): 1156159. Accessed April 1, 2020. doi:10.2307/954772. 
Sándor György. On Piano Playing: Motion, Sound and Expression. Belmont, CA: Wadsworth/Thomson Learning/Schirmer, 2007.

Sataloff, Robert Thayer., Alice G. Brandfonbrener, and Richard J. Lederman. Performing Arts Medicine. San Diego: Singular Pub. Group, 1998.

Shen, Xuan 谌萱. “Gangqin Yanzou Jishuzhong de Shengli Wenti Yanjiu” 钢琴演奏技 术中的生理问题探究 [Investigation on Physiological Problems in Piano Performance Techniques]. Hunan Shifan Daxue 湖南师范大学 (2006): 43.

Shields, Nora, and Sara Dockrell. "The prevalence of injuries among pianists in music schools in Ireland." Medical Problems of Performing Artists 15, no. 4 (2000): 155+. Gale OneFile: Health and Medicine (accessed May 19, 2020).

Singer, Kurt, and Wladimir Lakond. Diseases of the Musical Profession: a Systematic Presentation of Their Causes, Symptoms and Methods of Treatment. New York: Greenberg, 1932.

Sloboda, John. Exploring the Musical Mind: Cognition, Emotion, Ability, Function. New York: Oxford University Press, 2005.

Spahn, Claudia, Bernhard Richter, and Ina Zschocke. "Health Attitudes, Preventive Behavior, and Playing-related Health Problems among Music Students." Medical Problems of Performing Artists 17(1) (March 2002): 22-28.

Tubiana, Raoul, and Peter C. Amadio, eds. Medical Problems of the Instrumentalist Musician. London: Martin Dunitz, 2000.

Weissman, Barbara N. Imaging of Arthritis and Metabolic Bone Disease. Philadelphia, PA: Saunders Elsevier, 2009.

Williamon, Aaron, and Sam Thompson. "Awareness and Incidence of Health Problems among Conservatoire Students.” Psychology of Music 34(4) (2006): 411-430.

Winspur, Ian, and Wynn Parry Christopher B. The Musicians Hand: a Clinical Guide. London: Martin Dunitz, 1998.

Wristen, Brenda G. "Overuse Injuries and Piano Technique: A Biomechanical Approach." Ph.D. dissertation, Texas Tech University, 1998. 
Zaza, Christine. "Prevention of Musicians' Playing-related Health Problems: Rationale and Recommendations for Action." Medical Problems of Performing Artists 8(4) (December 1993): 117-121.

Zetterberg, Carl, Helena Backlund, Jenny Karlsson, Helen Werner, and Lars Olsson. "Musculoskeletal Problems among Male and Female Music Students." Medical Problems of Performing Artists 13(4) (December 1998): 161-166. https://doi.org/10.1136/bmj.1.1365.441. 